\title{
Maximizing the Life of Lubricating Oils for Resources and Environmental Sustainability through Quality Monitoring in Service
}

\author{
Binfa Bongfa ${ }^{1 *}$, S. Syahrullail', M. K. Abdul Hamid', P. M. Samin', Barnabas Atuci and H. E. Ajibili ${ }^{3}$ \\ 'Faculty of Mechanical Engineering, University Teknologi Malaysia, 81310 UTM, Skudai, Johor, Malaysia; \\ engrbinfabongfa@gmail.com \\ ${ }^{2}$ Mubeco Petroleum Company Limited, P. O. BOX 386, Kaduna, Nigeria. \\ ${ }^{3}$ Mechanical Engineering Department, Federal Polytechnic, Idah - 271101, Kogi State, Nigeria
}

\begin{abstract}
Objective: To establish that in-service quality monitoring of lubricants as opposed to oil change intervals recommended by the oil/equipment manufacturers is more economical and can preserve the environment and resources. Methods/ Statistical Analysis: A pilot study conducted in capital cities of eight states in Nigeria to estimate the volume/annum of crankcase oils being drained from Nigeria used vehicles without confirming the true states of the oils. Used oil sample drained from a CAT3616-generator running on 1700 liters, at the replacement cycle (1000 hours) recommended by the oil/equipment manufacturer was tested in the laboratory and compared with data of a new oil sample from the same supplier. Findings: In this study, the economic, environmental, and resource conservation benefits of in-service lubricant testing are seen to be outstanding compared to the standardized maintenance schedules recommended by the oil/ equipment manufacturers. The pilot study conducted in capital cities of eight states in Nigeria revealed that huge volume of crankcase oil, which may still be very serviceable, are being drained from Nigerian used vehicles, available in densely populated cities. Used oil, drained at a predicted replacement cycle of 1000 hours, from a CAT 3616 generator running on around 1700 liters, was discovered still serviceable, when tested and compared with data of a new oil sample from the same supplier, tested for benchmarking. Applications/Improvements: Through In-service monitoring of lubricating oils, the OEM regulation can be effectively moderated without causing damage to the equipment, and it can result in economic savings, and environmental/resources sustainability.
\end{abstract}

Keywords: Cost/Resources Conservation, Environmental Sustainability, In-Service Test, Lubricants Life, Oil Change

\section{Introduction}

Over time, the effectiveness of lubricants is reduced due to degradation $\frac{1,2}{2}$ and they need to be replaced ${ }^{3}$, amounting to undue resource wastage. The frequency is dictated by the type of equipment or recommendations by the oil manufacturer. Compliance to equipment manufacturer's instructions is generally high, as there are safety issues involved and equipment warranties may be affected by lapses in service and maintenance directives ${ }^{3}$, even when it is costly. The life of a lubricant is generally based on the schedules provided by Oil and Equipment Manufacturers (OEM), but maximising the intervals between lubricant replacements is also important.

Most change intervals are based on time factors or distance $^{2}$ as in moving equipment, which can be conservative. Maximum use of resources can be achieved, if scientific monitoring is undertaken without an interruption in the equipment working-hours. In-service monitoring allows for a lubricant to be changed, based on its actual condition, rather than by strict adherence to maintenance schedules. 
Lubricant efficiency is important to the life of equipment, and the awareness of the lubricant degradation will ensure the equipment is not damaged. However, events may take place that can cause the replacement cycle to be irrelevant, and although the recommended period or distance is not due, action may need to be taken. The lubricant may get deteriorated in some way and reduced efficiency may ensure, causing wear at a faster rate than anticipated. Both the manufacturers of lubricating oils and of the equipment provide comprehensive specifications from their respective perspectives on quality and performance control. Extensive collaboration takes place between OEM, to determine the quality and specifications for lubricants. The expected performance in machinery is predicted, and this governs the manufacturing of oils and equipment. However, in-service monitoring of lubricating oils is an important aspect that may lead to moderation in the OEM regulation without causing damage to the equipment. Where there is unpredicted oil failure, equipment failure also becomes inevitable. For an internal combustion engine, the failure occurs over time within which its performance will be inefficient or rough causing un-usual emissions or poor fuel combustions which has some serious repercussions on both the engine and the environment.

There are a number of oil analysis methods which can reveal the true condition of oil in service, and help in the effective maximization of its life. These include testing the acid and base numbers, peroxide value, water content, corrosion resistant level, and other variables related to oxidation resistance of the oil, and viscosity-temperature characteristics of the oil. They can scientifically report on the oil quality and determine a schedule for replacement, based on deterioration in the condition of the lubricant, rather than OEM time-based on distance-based directives. Strategic oil analysis is an effective means of confirming the condition and the remaining effective life of an oil ${ }^{3,4}$, leading to maximization of the lubricant life, rather than incurring considerable expenses related to replacement, machinery downtime, reduced productivity and disposal due to premature draining of the oil ${ }^{4,5}$. Lubricant in machinery is tested at sample points available in the system, normally at the machinery's life zone upstream of filter ${ }^{6}$, using a range of relevant standard test procedures. Guidelines covering testing have been issued by a number of experts, including the American Society for Testing and Materials (ASTM), The Institute of Petroleum (IP) in the UK, International Organisation for Standards (ISO) and Society of Automotive Engineers (SAE). Methods, including Infrared Spectroscopy ${ }^{1}$, Fourier Transform Infra-red Spectroscopy ${ }^{1,7}$, Foster-Miller's On-Line Oil Condition Monitor ${ }^{8}$, In-Line Oil Debris Monitor ${ }^{2}$ and others ${ }^{10}$, are available for in-service monitoring.

If the quantity of lubricating oil is small, the several of the impacts that may arise are likely to be assumed negligible. However, the environmental impact cannot be seen in the same inconsequential perspective, because it is established in literature ${ }^{11}$ that even very humble quantity of mineral oil can be harmful to aquatic habitat and hindered trees from growing. For systems such as crankcases in ships, reservoirs in large hydraulic presses or cranes, or quenching baths in metal working plants, railway internal combustion engine, and large power generators all involve high volumes of oil, it cannot be argued that premature changes have serious wastages and environmental implications. As expressed by ${ }^{12}$, the rate of oil degradation and additives depletion, are functions of many variables (including operation temperature of the machine, the load, environment, the idealness of the choice of the viscosity of the oil, and level of its cleanliness). Replacing hydraulic oil based on service-hour without relevant information about its actual condition, is synonymous to "shooting in the dark". Considering the current value of oil and the extent of eco-pollution cause by used oil, the continued dumping of oil that is not due for replacement is a thing not expected of a professional. Although manufacturers' recommendations are important, most oil changes are carried out with less precision, based on established rule of thumb, or individual machinery operating schedules. Modern technology has replaced arbitrary inspection, and provides inexpensive and reliable test methods that can determine the life of a lubricating oil, so that it is replaced only when necessary ${ }^{1}$. Prudent sampling, testing and analysis may determine the remaining life of a lubricant, even though the OEM recommendations may differ. When samples are taken from the correct locations, it can lead to extended oil drain intervals, which can save cost, preserve environment and resources without causing damage to the equipment.

Most published articles on oil analysis and oil change intervals concentrate on machine safety without consideration of the cost, resources, and environmental implications of these conservative changes. However, there are cases of practical industrial experiences bringing the awareness that oil change interval resulting in conserving cost and resources, and preserving the envi- 
ronmental could be safely done. A case of possible savings from condition-based oil change is documented in an article $e^{\underline{13}}$. This scenario was at a large Canadian pulp and paper mill. The steam plant engineer ordered an oil change, after 5 years of usage on the lubrication system of the main turbo generator. The cost of the oil alone was $\$ 54,000$, and additional costs would involve manpower and disposal, apart from machine downtime. The reliability team leader recommended in-service testing by laboratory analysis and also performance-based tests, including Rotating Pressure Vessel Oxidation Test (RPVOT), demulsibility, resistance to foaming, and resistance to corrosion tests. The resulting data showed that oxidation resistance of the oil was still between $90-95 \%$ and there were no matter of concern regarding wear, demulsibilty, particles and water contaminants, or foaming. At a cost of under $\$ 500$ incurred to carry out the various analyses, an expense of $\$ 54,000$ had been averted, as well as costs associated with shutdown, maintenance, unnecessary loss of manhours, disposal and environmental effects. In ${ }^{14}$ reported that lost production, administrative processes, labour and supervision, storage and handling costs, and purchasing and quality assurance, normally exceed the cost of the oil by a factor of 40 . The same principle applies to changing filters. Based on OEM specifications of interval-based oil changes, which is four times per year for some large volume oil using equipment, if the condition of the oil is satisfactory and one oil change can safely be avoided, the company can save $140 \%$. An undated report $t^{15}$ reveals that over time, the most effective and popular trend in machineries and lubricating oil condition monitoring is oil analysis. This monitoring actively addresses economic and environmental incentives and keeps them in line with the safe and efficient running of the equipment. Corporate organisations had expressed interest in evaluating the condition of oil lubricants rather than adhering blindly to OEM recommendations. Industries such as logistic firms that deploy big commercial fleets, operators of railways, or power generation plants, are particularly motivated by the incentives of maximising lubricant life $\frac{3,4}{3}$.

The present paper established that in-service oil analysis leading to extended oil drain periods can result to huge oil-cost savings (without affecting the life of equipment), conserve resources and ensure environmental preservation. It is divided into four parts. The authors presented environments and resource sustainability through extended oil drain periods, stated several life examples, reported a pilot study on oil drain periods in Nigerian automotive repair workshops. An oil sample test results from a 4 MW CAT 3616 generator drained at the end of 1000 hours of operation (recommended by OEM), were compared with a new oil sample from the same supplier, tested under the same conditions, to justify these claims. The technicalities of in-service monitoring, the reliabilities of in-services tests, and the benefits of extended oil drain periods were also presented.

\section{Environment and Resources Sustainability}

Petroleum resources are fast depleting, and this projects uncertainty in their future availability $11,16,17$. Processing lubricant from petroleum consumes a lot of energy, and cause environmental pollution. The disposal of the used lubricants, no matter how small, which we are aware are not bio-degradable, will cause harmful impacts on the environment. According to $\frac{18}{}$, petroleum derived oil is capable of contaminating groundwater for a period of 100 years, and that 0.1 part per million of this oil can cut short the life of shrimps by $20 \%$. He added that 10 litres of mineral oil poured on the ground was monitored in an experiment to have $20 \%$ still remaining in the ground at a depth of $150 \mathrm{~mm}$ after 10 months. Apart from the incentives from economic angle, prolonged change interval of lubricant will preserve energy and resources, and also relieve the environment from the pressure of pollution as a result of indiscriminate disposal of the oil. The inter-connectivity within the economy, sustainability and environment, relating to lubricant use was visualized 19 . His view is that, the concept of sustainability as part of economic development also led to formulation of policy covering effective utilization of lubricants lives. This was done for optimal sustainability and environmental protection. $\operatorname{In}^{20}$ emphasized the savings of energy, resources, and reduction of the impact on environment as the most important pursuit of eco-tribology. He estimated that the rate at which petroleum resources is being utilised, may lead to its exhaustion in 100-300 years, and that the amount of primary energy being saved from the extraction and processing of raw materials is just between $25-30 \%$ of the total consumption. These are facts among others to be upheld in many critical considerations, like is being done herein. Among his views is that, an increase in energy savings, and sustainability of non-renewable resources and environment can be achieved, by "extended 
lubricant change periods". Again $\frac{19}{}$, estimated that the energy requires to process petroleum base oil is $9 \mathrm{MJ} / \mathrm{kg}$ (against approximately $42 \mathrm{MJ} / \mathrm{kg}$ - the "Energy of Material Resource (EMR)" of the product)which is about $21 \%$. To manufacture additives for lubricants and hydraulic fluids is $35 \mathrm{MJ} / \mathrm{kg}$ (against $40 \mathrm{MJ} / \mathrm{kg}$ - the EMR of the product) this is $87.5 \%$, and for blending to get the final product is $3.6 \mathrm{MJ} / \mathrm{kg}$. Putting these together among other considerations, he concluded that the most significant contribution that lubricants can make to sustainability will come from "extended operating service intervals". The opinions from these sources show that extended oil-change interval is a key player in resources and environmental sustainability.

The world has a promise of eco-friendly and sustainable fuels and lubricants for energy, through bio-based sources. But so far, the availability is grossly in-adequate, because there are recent records showing that between $85 \%$ to over $95 \%$ of the lubricants used in the world are from petroleum $\frac{16,21,22}{}$. Moreover, the performance of the products from bio-based sources are yet to meet service requirements of some of the machineries using huge volume of lubricants, and high performance fluids, due to the challenges with the triglyceride structures of the base materials. Another thing is that, the eco-friendly and readily biodegradable lubricants still have some level of toxicity and persistence in the environment, mostly due to the additives packages used in their formulation $^{23}$ and the contaminants they procure, and chemical transformations they undergo in service. Therefore, our environment - soil, air, ground and surface water, still have needs of minimal contact with them as much as possible. Furthermore, their usage, particularly the edible oils, for lubricants, metal working fluid ${ }^{22}$ and biodiesel applications is stretching the food and agricultural industries $^{\underline{23}}$. These all boil down to the need for economic use of lubricants, which can be primarily ensured by extended lubricant life made possible by informed in-use analysis.

Re-refining of used oil (so far in progress in some part of the world) is contributing immensely in reducing pollution, cost of waste oil disposal, and resources sustainability ${ }^{24}$, but you will agree with these authors that each of the processes still requires processing energy, man power and machine time, apart from the risks. Draining the oil prematurely for processing will lay unnecessary demand on these arms of industrial cost and in turn stress the pocket of the consumers. It is envisaged that the waste product from used re-refined oil may be small in quantity but could contain concentrated toxic substances ${ }^{25}$. The issue of secondary pollution from co-combustion of used oil and sludge is still a challenge to be tackled ${ }^{26}$. The difficulties in used oils handling ${ }^{27}$ and stringent regulations on organisations and individuals connected with their generation, handling, transportation and reprocessing 28 , calls for reduction in oil draining. No doubt, a safe extension of drain time of the lubricant will definitely further reduce pollution and maximize usage of resources.

Lubricants extended change interval, will to a large extent, reduce the quantity of used oil being released to the environment. If one oil change is safely avoided out of the four times per year, specified by OEM, as illustrated by ${ }^{14}$, except for recycling earlier mentioned, 25\% per annum of used lubricant from such types of equipment is avoided in our environment. This means that, 200 million gallons of used lubricants released into the environment per year, according to the USEPA ${ }^{29}$, can be sliced down to 150 million gallons. Not only that, there will be $25 \%$ reduction in the quantity of lubricants demanded from lubricants marketers per year. This scale goes down to energy consumption and raw materials utilisation. Another study reported on Sishen Mine in South Africa, by the same author, revealed that oil condition monitoring ensured the extension of the service life of hydraulic oil used by the mine's haul trucks from 500 hours to over 1000 hours (when problem of wear suspension was taken care of). This will mean reduction in the quantity of oil used by those trucks by roughly over $50 \%$ per annum, slicing down the quantity of the hydraulic oil used, maintenance cost, waste oil environmental risk and disposal cost by at least half each year. A recent estimate by ${ }^{30}$ is that, a large paper mill buying lubricants worth $\$ 250,000$ per year could save $20 \%$ of the oil (i.e. $\$ 50,000$ ) each year, (and thrice this amount if other expenses from purchases to disposal are included) through extended change interval, as the service condition of the oil was carefully monitored. Again, from this paper mill, there will be reduction (by one-fifth, each year) of lubricant consumption, and also of the impact on the environment due to disposal of used lubricant. These are sample information depicting the extent of environmental benefits, and resource conservation, extended drain interval through in-service oil monitoring can contribute. As a matter of fact, maximising the life of lubricating oils should be seen as an "environmentally conformable" practice.

Environmental protection agencies are under pressure to set up a policy (as part of the demand on organizations to be eco-friendly ${ }^{19}$ ) through monitoring from time to 
time, the in-service test reports of users of huge volumes of lubricating and hydraulic oils at the various change times, to dissuade unnecessary pollution from the premature disposal of used oils especially when the in-service monitor parameters reveal that the oil still has serviceable life. The policy can be extended to vehicles maintenance garages, so that they employ the use of equipment such as handy Infrared (IR) Spectroscopy-ASTM (E2412), to test and record the condition of each oil they have to change for their customers and not just relying on time and or mileage specifications by OEM, which are mostly conservative. Infrared (IR) Spectroscopy-ASTM (E2412) gives detailed information about the contamination and degradation of oil ${ }^{31}$. This paper is stepping in to further accentuate the need for such close monitoring. Underrating the collection from automotive maintenance garages can be an expensive negligence as revealed by a pilot study in this current work. The pilot study was done on drainage of used oil in Nigeria automotive maintenance garages. The outcome reported is a serious eye opener to the extent of losses and environmental impediment reachable by their used oil handling activities.

\section{Technicalities of In-service Monitoring}

In-service monitoring compares the current properties and condition of the oil to a newly supplied sample or to the equipment manufacturer's oil specification. Steam and gas turbine machinery lubricants are assessed by three categories of tests, examining the physical and chemical properties, taking contamination measurements and evaluating performance properties. Standardised lubricant testing should include viscosity (ASTM D445), viscosity index, relative density, oxidation stability (RPVOT, ASTM D2272; Pressurized Differential Scanning Calorimeter; Rancimat), water content (visual and ASTM D1744), total acid number (ASTM D974), demulsibility (ASTM D1401), particle count (ISO 4406), metal contaminants (Inductively Coupled Plasma), resistance to corrosion (ASTM D665 A and B) and foaming. In $^{32}$ also emphasized test for viscosity at 40 and at $100^{\circ} \mathrm{C}$, water content (ASTM D 4928), insoluble materials (ASTM D 893) and the use of Fourier Transform-Infrared Spectroscopy (FT-IR) for rapid determination of relevant parameters. Of recent, FT-IR was given preference over conventional ASTM methods ${ }^{1}$.
Functional and chemical tests are more informative in predicting in-service lubricant performance than physical tests, although the latter are less expensive ${ }^{33}$.

Unfortunately, most technicians, especially those carrying out maintenance work, like automotive repairs, rely solely on physical tests only. Worse still, in Nigeria, they have cheap and quicker access to the more unreliable test equipment of the physical tests.

Accurate prediction requires a comparison of the results of the same parameters obtained using the same test methods and conditions. An example is the flash point test results from the open cup method should never be compared to closed cup tests, the latter being an inadvisable method. Standardised test methods have been developed over a long period and are designed to compare results at different stages in the life of the lubricants $s^{35}$.

\section{Reliability of In-service Test}

The reliability of standardized in-service test method results for machineries generally, are well recognised and are usually employed to increase machineries uptime ${ }^{34}$. With in-service oil analysis, the results have been quite revealing. Experts involved in vibration accepted that oil analysis always reveals wears in machines earlier than vibration analysis does. To identify the problem and ultimately the root cause of varnish and sludge, routine quantitative in-service spectrophotometric analysis and ultracentrifuge tests of the oil are carried out $\frac{35}{}$. These tests better quantify the performance of oil lubricants, apart from its current physical appearance and properties. The results can prove that the oil has not undergone chemical changes or contains serious contaminants, which would necessitate its change. Problems may be restricted to water or particle ingress, which causes degradation to the additives or the base oil. Identification of this type of condition would require only filtration and not changing the oil. The maintenance team members carrying out in-service testing require a high degree of skills and experience in taking samples, operating the testing equipment and in interpreting the test data ${ }^{6}$. Innovative methods require additional training of staff to implement methods and operate newly developed equipment. Instead of making huge and tasking investments on various test equipment, it is usually cheaper to manage an arrangement with accredited laboratories to which the samples can be sent 
at agreed fees. This method is operated by the Standard Organisation of Nigeria (SON).

Increased sediment ratio can be an indication of increased wear of equipment parts, usually resulting from insufficient lubrication of the engaging surfaces. However, it may also be contingent on an unusually drastic reduction in the viscosity, caused by the result of light fraction ingress into the oil. In the case of an internal combustion engine, fuel dilution of the oil may be the cause. Characteristics that are critical in one system may not be of great concern in another. For example, in a hydraulic or gear system, foaming cannot be tolerated as it leads to breakdown of the lubrication and consequent metal-to-metal contact. This is not an issue in crankcase lubrication. Similarly, in gasoline engines, the oil is permitted to emulsify, as water is formed during the running of the engine. Water ingress into the oil in marine engines using large residual fuels is high, because of the working environment of sea water. In this case, demulsification is required, where the engine oil is subjected to water-washing to remove the acidic components of combustion, and the oil and water are easily separated. These examples are given to imply that lubricating oil conditions should not be generalised, but taken on the merits of system operating conditions that will individually affect degradation or depletion in quality. Well supported analysis of the test results is the rationale behind in-service testing that leads to good maintenance of equipment and maximisation of the life of the lubricant.

The chemical tests are confirmatory test $\mathrm{s}^{33}$ and where they are within standard ASTM and IP recommended methods for such tests, there may be no need to undertake functional tests and purely physical tests. The condition of an oil sample from a 4MW CAT 3616 generator before and after it had been run for 1000 hours; a typical OEM time recommendation is reported.

\section{Results and Discussion}

Table 1 shows the number of vehicles per day each automotive maintenance garage in eight major cities in Nigeria changes used engine oils for. The data were collected by administering a questionnaire to 5 auto-mechanic shops in each of the cities. This data reveals volumes. Unfortunately, Nigeria, just like any other African country, has very weak environmental legislations and so, used oils disposal is done at ease ${ }^{36}$. There is no record of exis- tence of any used oils refinery in Nigeria ${ }^{37}$. At best, there are various proposals to build re-refined used oil plants. Nigerian blenders are just proposing to send a bill on collection and disposal of waste oil to the legislature $e^{37}$. Best known to the authors of this work, the used oils, locally called "condemned engine oils" are mostly used by wood sawing mills as total lost lubricants, and by some rural and semi-urban areas as pesticide for termite control. $\mathrm{In}^{\frac{38}{}}$, reported that some mechanics pour the used oil on ground as dust suppressor, blend them with greases for use as gear oils, and also recycle them untreated in worn engines. The last two may be of cost and environmental benefits, but risky, since the status of the drained oils are not properly determined. Further, the used oil is used by some companies as fuel to fire their boilers and furnaces ${ }^{3 .}$; another heavy source of pollutant, used as wood preservatives, herbicides, block mold lubricants, and on metal surfaces as rust and corrosion control agents. All these end up in our eco-system. A simple analysis will show that for an average sump size of 4 liters, around 27 liters is collected by one auto-maintenance shop per day, around 972 liters by one shop in each of the 36 states, put together. For 5 working days a week, and 52 weeks of the year, the total oil collected by one shop in each of the states, put together is 253,000 liters. This does not include the trucks and other heavy on-road vehicles.

Table 1. Pilot study on automotive engine oils change in Nigeria

\begin{tabular}{|l|l|l|}
\hline City & $\begin{array}{l}\text { Number of } \\
\text { Auto-technicians } \\
\text { interviewed }\end{array}$ & $\begin{array}{l}\text { Average Number of } \\
\text { Vehicles Serviced/day }\end{array}$ \\
\hline Kano & 5 & 4 \\
\hline Lokoja & 5 & 2 \\
\hline Kaduna & 5 & 5 \\
\hline Lagos & 5 & 5 \\
\hline Abuja & 5 & 10 \\
\hline Jos & 5 & 9 \\
\hline Yola & 5 & 8 \\
\hline Sokoto & 5 & 11 \\
\hline
\end{tabular}

The methods used to diagnose these in-service automotive oils expiration before they are recommended for change by most automotive mechanics in Nigeria, as obtained from the pilot study is represented in Figure 1. While methods such as faults, including abnormal 
exhaust emission, abnormal engine sound, low engine speed, and engine overheating may be probably due to worn-out rings, wrong settings, weak compression, and top cylinder gasket failure respectively, up to $9.26 \%$ of the interviewed auto-mechanics do classify them as oil expiration conditions. These are unprofessional conclusions on the oil conditions. Other unprofessional approaches are hand estimation of viscosity, decrease in oil level from the gauge, and users demands, which are practiced by such large proportions indicated on the chart in Figure 1. The professional practices being upheld by these mechanics are mileage, dashboard indicators, and oil appearance. While the first two professional practices are the OEM conservative approaches which recommend oil change without ascertaining its true life, the latest practice is based on just the least parameter of physical test which cannot be a confirmatory representation of the oil condition. Based on these unprofessional, OEM recommendations, and the weakest physical test parameters the automotive workshops adhere to, an astronomical portion of the estimated quantity of the oil drained from the vehicles may still be serviceable. Since no functional re-refining company is available in Nigeria, these huge volumes are potential eco-pollutants.

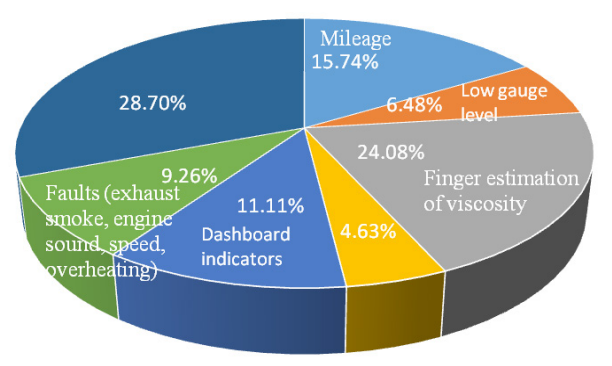

Figure 1. Pilot study on the bases of draining automotive engine oils by Automotive Workshops in Nigeria.

The CAT 3616 generator runs on distillate fuel for which one oil change would require 8 drums or about 1700 litres. Column 5 of Table 2 shows that even after 1000 hours, the oil is still very serviceable. At a figure of $22.5 \mathrm{mgKOH} / \mathrm{g}$, the total base number which defines the acid neutralization capabilities of the oil may appear low when compare with the Representation Standard Recommendation value. However, the engine was running on $0.5 \%$ sulphur content fuel (a supposedly low sulphur fuel) which requires oil with less total base number, because acidic corrosion from a low sulphur containing fuel are generally low ${ }^{39}$. Therefore, the current total base level of the oil is still very adequate. This equally explains the position of the lower sulphated ash content of the used oil in the study. This is based on the fact that sulphated ash content of an engine oil is directly related to the total base number of the oil, as documented in the literature ${ }^{39}$.

The change in kinematic viscosity at $100^{\circ} \mathrm{C}$ from 15.39 to 16.33 cSt still places the oil in the SAE 40 viscosity range. However, even in the SAE 50 viscosity range, it will suffice, because the average ambient temperature in the working environment is about $32^{\circ} \mathrm{C}$. The viscosity index of the oil is still higher than the representation standard recommended. This implies that the variation of the viscosity with temperature is still good enough to provide lubricity and cooling at high engine temperatures and speed. The flash point of the studied in-service oil showed that the oil still has low evaporation loss and low flammability.

Considering the physical size of the engine in question, the volume of the product of combustion being "exhausted" per time will contain a substantial volume of water in the gaseous state. The engine cooling process enabled by the engine oil will cause condensation of some of the water vapour and be ejected into the oil in service; and retained by the detergency characteristic of the oil. Being less than $0.5 \%$ makes the water content of $0.2 \%$ tolerable. The variation in specific density of the used oil to the new oil is just about $7.36 \%$. By this, the estimated oxidation degradation, and contaminant level of the oil is still very low, from which it can be inferred that the oil is still serviceable.

By these results, the oil still retains some useful life and replacing the oil at this point in time will not only have negative economic and environmental impacts, but will also not be in line with sustainability concept, as exhaustively discussed in section 2 and 3.

\section{Benefits}

The benefits from in-service oil quality monitoring include:

- Reduction in disposal costs, reduction in new fluid purchases, and in maintenance costs (by exhausting to optional level, the potent life of the oil), and in machine down-time (implying increased plant availability or machine running 
Table 2. Characteristics of a high quality sae 40 (APL: CF) diesel marine engine oil (before and after use)

\begin{tabular}{|l|l|l|l|l|}
\hline Parameter & $\begin{array}{l}\text { Test } \\
\text { Method } \\
\text { ASTM }\end{array}$ & $\begin{array}{l}\text { Product } \\
\text { Supplied }\end{array}$ & $\begin{array}{l}\text { Representation } \\
\text { Standard } \\
\text { Recommendation }\end{array}$ & $\begin{array}{l}\text { After 1000 } \\
\text { hours } \\
\text { Usage }\end{array}$ \\
\hline Appearance & visual & B\&C & B\&C & Dark \\
\hline Colour & D1500 & 4.0 & 4.6 & 8.5 \\
\hline $\begin{array}{l}\text { Specific Gravity @ } \\
15^{\circ} \mathrm{C}\end{array}$ & D1298 & 0.9094 & 0.894 & 0.9161 \\
\hline $\begin{array}{l}\text { Viscosity in cSt @ } \\
40^{\circ} \mathrm{C}\end{array}$ & D0445 & 138.62 & Report & 170.9 \\
\hline $\begin{array}{l}\text { Viscosity in cSt @ } \\
100^{\circ} \mathrm{C}\end{array}$ & D0445 & 15.39 & 14.4 & 16.33 \\
\hline Viscosity Index & D2270 & 114 & 90 & 99 \\
\hline $\begin{array}{l}\text { Total Base Number } \\
(\mathrm{mgKOH} / \mathrm{g})\end{array}$ & D2896 & 40.3 & 40.2 & 22.5 \\
\hline $\begin{array}{l}\text { Flash point (COC) } \\
\left({ }^{\circ} \mathrm{C}\right)\end{array}$ & D0092 & 220 & 245 & 236 \\
\hline $\begin{array}{l}\text { Water content } \\
(\% \text { vol.) }\end{array}$ & D0095 & NIL & NIL & 0.2 \\
\hline $\begin{array}{l}\text { Sulphated Ash } \\
\text { content (\%wt) }\end{array}$ & D0874 & 5.1 & 4.9 & 3.7 \\
\hline Particle count & - & - & - & - \\
\hline
\end{tabular}

time) which, by many applications, can result in significant cost saving to the user ${ }^{40}$.

- Improved operator and user safety due to known condition of the machine through early warning signals obtained from various analysis and prognosis, enabling stoppage of machines before critical condition or break-down ${ }^{41}$.

- In-service monitoring data and detailed records will lead to negotiation of favourable terms between performance and operating life. This will increase the time until the next complete maintenance, leading to more efficient running of the plant, more uniform satisfactory output, and possibility of identifying clearly and designing more efficient plants in the future ${ }^{41}$.

- A longer interval between the replacements of oil will lead to a reduction of environmental pollution, caused by disposal of the used oil. It will reduce the rate of environmental degradation, and global warming that may stem from lubricant disposal activities.

- Considerable reduction of pressure on the lubricants markets, and subsequently on the lubricants manufacturers, with respect to pro- vision of products that will leave lesser negative impact on the environment in their functioning.

\section{Conclusion}

In this study, it is revealed that in-service quality monitoring of lubricating oil, leading to moderation in the OEM regulation without causing damage to the equipment, can maximise the life of the lubricating oils, conserve resources and ensure environmental sustainability. Secondly, extending the policy of in-service quality monitoring of lubricating oil to large number of users of machineries running on small quantity of lubricating oil, such as vehicle users in a city is a necessity, considering the huge volume of oil collection per year from the automotive maintenance garages from the pilot study carried out in eight state capital cities in Nigeria.

The criteria that guide the OEM recommended practices are based on conservative parameters that aim to place equipment use within very safe regimes, optimum lubrication performance, and complete avoidance of potential machine breakdown, disregarding environmental protection and sustainability to a large extent. 
However, a comparison of new oil from the supplier, and used oil from the plant (taken immediately after the recommended time for a change by OEM), under controlled tests reveals that the used oil is still in good condition. This is indicative that most of the time, economic losses and environmental harm are not justified as the quality of the oil remains acceptable and need not to be changed at the time recommended. In-service oil monitoring systems as opposed to reliance on recommended practices can enable the full life of the oil to be put to use, without any risk to operators or machinery. When a conscious decision is taken to adopt in-service monitoring, predictive tests can consistently show the oil condition parameters with a high level of accuracy, and extend the oil change intervals incrementally to a safe final level. When the volume of oil used in machinery is small, the cost of inservice monitoring may outweigh the benefits, though the cumulative impact on the environment can be significant. The cost-benefit ratio is too low to call for extensive testing and the resources required. Environmental cost can be discreetly considered based on the level of toxicity and biodegradability of the oil. However, machinery that involves larger volumes of lubricants brings into perspective the application of in-service testing, as there are considerable cost savings, resource savings, and environmental preservations to be achieved.

\section{References}

1. Voort F, Sedman J, Cocciardi R, Pinchuk D. FTIR condition monitoring of in-service lubricants: Ongoing developments and future perspectives. Tribology Transactions. 2006 Feb; 49(3):410-8.

2. Van de Voort F, Sedman J, Pinchuk D. An overview of progress and new developments in FTIR lubricant condition monitoring methodology. Journal of ASTM International. 2011 May; 8(5):3314-44.

3. Caines AJ, Haycock RF. Automotive Lubricants Reference Book. $2^{\text {nd }}$ ed. Warrendale: SAE International; 2004. p. 760.

4. Bart JC, Cavallaro S. Gucciardi E. Bio-lubricants: Science and Technology. $1^{\text {st }}$ ed. Cambridge: Wood Head Publishing Limited; 2012. p. 944.

5. Schalcosky DC, Byington CS. Advances in real time oil analysis. Practicing Oil Analysis Magazine. 2000:28-34.

6. Fitch JC. Elements of an oil analysis program. Tribology Data Handbook. Boca Raton \& New York: CRC Press LLC; 1997. p. $875-88$.

7. Toms AM. FT-IR for effective, low-cost oil condition monitoring. Technical Paper; 2000 Nov. p. 26-31.
8. Chadha S. Foster-Miller's on-line oil condition monitor, a cost-effective cross-platform tool for condition-based maintenance. Lubricant Fluid Power Journal. 2000; 1(1):2630.

9. Miller JL, Kitaljevich D. In-line oil debris monitor for aircraft engine condition assessment. IEEE Aerospace Conference Proceedings; 2000. p. 49-56.

10. Jakoby B, Buch S, Schatz O. Method for assessing the deterioration of motor oil. Google Patents. 2004.

11. Willing A. Lubricants based on renewable resources - An environmentally compatible alternative to mineral oil products. Chemosphere. 2001 Apr; 43(1):89-98.

12. Casey B. The seven most common hydraulic equipment mistakes. 2014. Available from: http://bit.ly/2gXcpmF

13. Squeezing every last cent from your oil. 2014. Available from: http://bit.ly/2gXdNFB

14. Hoffman P. Extending oil change intervals on heavy mining equipment. 2015. Available from: http://bit.ly/2gFBKmX

15. Signum technical guide. 2015. Available from: http://exxonmobil.co/2fYRceI

16. Joseph P, Sharma D. Improvement of thermo-oxidative stability of non-edible vegetable oils of Indian origin for biodegradable lubricant application. Lubrication Science. 2010 Apr; 22(4):149-61.

17. Nakkeeran S. Technology for emission reduction by blending methanol, ethanol and biodiesel with diesel. Indian Journal of Science and Technology. 2015 Nov; 8(31):1-6.

18. Wilson B. Lubricants and functional fluids from renewable sources. Industrial Lubrication and Tribology. 1998 Feb; 50(1):6-15.

19. Fox MF. Environmental implications and sustainability concepts for lubricants. Handbook of Lubrication and Tribology: Volume I, Application and Maintenance. In: Totten GE. Editor. Boca Raton: CRC Press; 2006. p. 32-130.

20. Bartz WJ. Ecotribology: Environmentally acceptable Tribological practices.Tribology International. 2006 Aug; 39(8):728-33.

21. Pop L, Puşcaş C, Bandur G, Vlase G, Nuţiu R. Basestock oils for lubricants from mixtures of corn oil and synthetic diesters. Journalof the AmericanOil Chemists' Society. 2008 Jan; 85(1):71-6.

22. Lawal SA. A review of application of vegetable oil-based cutting fluids in machining non-ferrous metals. Indian Journal of Science and Technology. 2013 Jan; 6(1):3951-6.

23. Suhane A, Rehman A, Khaira H. Potential of non-edible vegetable oils as an alternative lubricants in automotive applications. International Journal of Engineering Research and Applications. 2012 Oct; 2(5):1330-5.

24. Betton C. Lubricants and their environmental impact. Chemistry and technology of lubricants. In: Mortier MR, 
Fox MF, Orszulik ST, editors. Springer: Netherlands; 2010. p. 435-57.

25. Kajdas C. Major pathways for used oil disposal and recycling. Part 1.Tribotest. 2000 Sep; 7(1):61-74.

26. Liu Q, Jiang P, Zhao J, Zhang B, Bian H, QianG. Life cycle assessment of an industrial symbiosis based on energy recovery from dried sludge and used oil. Journal of Cleaner Production. 2011 Oct; 19(15):1700-8.

27. Kanokkantapong V, Kiatkittipong W, Panyapinyopol B, Wongsuchoto P, Pavasant P. Used lubricating oil management options based on life cycle thinking. Resources, Conservation and Recycling. 2009 Mar; 53(5):294-9.

28. Guerin TF. Environmental liability and life-cycle management of used lubricating oils. Journal of Hazardous Materials. 2008 Dec; 160(2):256-64.

29. Basic information about used oil common wastes and materials. 2014. Available from: http://bit.ly/2gs1cZT

30. Zhao Y. Oil Analysis Handbook. 2014. Available from: http://bit.ly/2g1wgyL

31. Toms LA, Toms AM. Lubricant properties and test methods. Handbook of Lubrication and Tribology: Volume I Application and Maintenance. In: Totten GE, editor. Boca Raton: CRC Press; 2006. p. 30-1-33.

32. Lukas M, Anderson DP. Laboratory used oil analysis methods. Tribology Data Handbook: An Excellent Friction,
Lubrication and Wear Resource. In: Booser ER, editor. Boca Raton \& New York: CRC Press; 1997. p. 897-913.

33. Lansdown A. Lubrication and Lubricant Selection: A Practical Guide. $1^{\text {st }}$ ed. London: Professional Engineering Publishing Limited; 2003. p. 286.

34. Satishkumar R, Sugumaran V. Estimation of remaining useful life of bearings based on support vector regression. Indian Journal of Science and Technology. 2016 Mar; 9(10):1-7.

35. Truong N. Today's Varnish Control Technologies. 2014. Available from: http://bit.ly/2gcq2iW

36. Umejei E. Africa Ponders Biolubes' Potential. 2015. Available from: http://bit.ly/2gUVOPL

37. Umejei E. Nigerian blenders support waste oil bill - lube report. Available from: http://bit.ly/1YYEKIx

38. Bamiro OA, Osibanjo O. Pilot study of used oils in Nigeria. Report of Study sponsored by the Secretariat of the Basel Convention. 2013; 15:100-65.

39. Ludwig L. Heavy duty diesel engine, oil development and trends. 2016. Available from: http://bit.ly/2guYNh4

40. Madhavan P, Werner NC. Contamination control for extending fluid service life. Available from: http://bit. ly/2haPQNV

41. Neale MJ. The Tribology Handbook. $2^{\text {nd }}$ ed. Oxford: Butterworth-Heinemann; 1995. p. 1-582. 